\title{
Physicochemical characteristics and fibril-forming properties of collagen from paddlefish (Polyodon spathula) and globefish (Fugu flavidus) skin byproducts
}

\author{
Shanshan WANG ${ }^{1}$, Xiaoqi SUN ${ }^{1}$, Deqing $\mathrm{ZHOU}^{1 *}$
}

\begin{abstract}
Acid-soluble collagen (ASC) and pepsin-soluble collagen (PSC) from the skin byproducts of paddlefish (ASC-P and PSC-P) and globefish (ASC-G and PSC-G) were purified and characterized. The imino acid contents of ASC-P, PSC-P, ASC-G and PSC-G were 194.1, 197.9, 186.4 and 189.7 residues/1000 residues, respectively. SDS-polyacrylamide gel electrophoresis (SDS-PAGE) and Fourier transform infrared spectroscopy (FTIR) confirmed that all four samples composed of two different a1- and $\alpha 2$-chains with integrated triple-helical structure. Denaturation temperatures of ASC-P, PSC-P, ASC-G and PSC-G were 29.6, 28.2, 27.4 and $26.9^{\circ} \mathrm{C}$, respectively. Based on Transmission electron microscopy (TEM) observation, all four samples could assemble into fibrils in vitro with D-periodicity. However, the fibril-forming rate of ASC-P and PSC-P was more rapid than that of ASC-G and PSC-G. Scanning electron microscopy (SEM) analysis confirmed well-defined fibril morphologies, the diameter of fibrils from ASC-P and PSC-P was thicker than those of ASC-G and PSC-G after $24 \mathrm{~h}$ incubation. These results indicated that paddlefish and globefish skin collagens could be alternatives to terrestrial collagens for applications in food-packaging, nutraceutical and pharmaceutical industries.
\end{abstract}

Keywords: paddlefish; globefish; collagen; physicochemical property; fibril-forming property; fibril morphology.

Practical Application: Utilization of paddlefish and globefish skin byproducts by extracting collagen with good physicochemical and fibril-forming properties.

\section{Introduction}

Collagens are the most abundant proteins in mammals containing triple-helical domains which can range from most of their structure (96\% for collagen I) to less than 10\% (collagen XII). Fibrillar rearrangement of collagens is the foundation behind the mechanical properties of almost all load-bearing tissues (Exposito et al., 2010). Due to the high fibril-forming ability, biocompatibility and low immunogenicity, collagens have been considered as excellent natural biopolymers which are developed as sausage casings or packaging films of meat products in food industry, and tissue scaffolds or wound dressings in pharmaceutical fields (Cozza et al., 2016; Tang et al., 2015). Traditionally, industrial production of collagens is mainly from terrestrial animals such as bovine, porcine skins and tendons. However, food safety crisis and religious restrictions resulted in a demand for collagens from alternative sources, particularly from aquatic organisms (Pal et al., 2015). With the rapid development of seafood processing industries, huge quantities of fish byproducts accounting for approximately $50-80 \%$ of the total catch weight are produced, which have collagen as the most abundant protein (Li et al., 2013; Suárez-Jiménez et al., 2015).

Farmed paddlefish (Polyodon spathula) is originated in Mississippi River of North America. Huge economic benefits have been created by paddlefish aquaculture in China since 1988 (Shi et al., 2013). Meanwhile, farmed globefish (Fugu flavidus) has also become increasingly popular in Asian countries for its non-toxicity, unique flavor and high nutritional quality (Tao et al., 2012). However, the lack of high-valued products limits the further development of paddlefish and globefish industry. We believe both paddlefish and globefish skin byproducts can be the potential sources for collagen production, the market value of fish offal would be increased and the environmental pollution could be reduced. Currently, collagen from skin byproducts have been extracted from Spanish mackerel, unicorn leatherjacket, giant grouper and Nile perch (Muyonga et al., 2004; Ahmad et al., 2010; Li et al., 2013; Hsieh et al., 2016). Nevertheless, there is scarce information that systematically investigates collagen from paddlefish and globefish. Therefore, the objective of this study was to isolate and comparatively evaluate the physicochemical and fibril-forming properties of acid-soluble and pepsin-soluble collagen derived from these two skin byproducts.

\section{Materials and methods}

\subsection{Materials}

Paddlefish (Polyodon spathula) skin byproducts were obtained from Kunshun Aquaculture Development Company (Foshan, Guangdong, China). Globefish (Fugu flavidus) skin byproducts were collected from Liuxing Aquatic Product Company (Taizhou, Jiangsu, China). Raw materials were washed with cold water $\left(0-4^{\circ} \mathrm{C}\right)$ and cut into small pieces (approximately $1 \times 1 \mathrm{~cm}^{2}$ ). Prepared skin was stored at $-20^{\circ} \mathrm{C}$ until use. Pepsin 
(EC 3.4.23.1) was purchased from Sigma-Aldrich Chemical Company (St. Louis, MO, USA). High molecular weight marker was purchased from Solarbio Biotechnology Company (Beijing, China). Other reagents used were of analytical grade and purchased from commercial vendors.

\subsection{Extraction of collagen}

Extraction of collagen was conducted at $4{ }^{\circ} \mathrm{C}$ following methods of Singh et al. (2011) with continuous stirring. To remove non-collagenous proteins, thawed skin was soaked in $0.1 \mathrm{M} \mathrm{NaOH}$ $(1: 20 \mathrm{w} / \mathrm{v})$ for $24 \mathrm{~h}$ and then washed until neutral $\mathrm{pH}$. The skin was defatted with $10 \%$ butyl alcohol solution $(1: 20 \mathrm{w} / \mathrm{v})$ for $24 \mathrm{~h}$, and washed thoroughly. Subsequently, the pretreated material was homogenized in a homogenizer (JYL-C010, Joyoung Ltd., Zhejinag, China) and soaked with $0.5 \mathrm{M}$ acetic acid (1:50 w/v) for $48 \mathrm{~h}$. The mixture was centrifuged at $8000 \times g$ for $20 \mathrm{~min}$ with a centrifuge (ST16R, Thermo Scientific Ltd., IL, USA). The residues were re-extracted for $24 \mathrm{~h}$ and the supernatants were combined. The precipitate was obtained by adding $\mathrm{NaCl}$ to a final concentration of $0.9 \mathrm{M}$, and collected by centrifuging at $8000 \times g$ for $20 \mathrm{~min}$. The precipitate was redissolved in $0.5 \mathrm{M}$ acetic acid, dialyzed against $0.1 \mathrm{M}$ acetic acid for $24 \mathrm{~h}$ and distilled water for $48 \mathrm{~h}$. The resulting precipitates were lyophilized using a freeze dryer (CoolSafe 55, ScanLaf A/S, Lynge, Denmark) and referred to as "Acid-soluble collagen from paddlefish (ASC-P)" and "Acid-soluble collagen from globefish (ASC-G)".

Raw material was pretreated as described above to remove non-collagenous proteins and fat. After homogenization, the skin was soaked with $0.5 \mathrm{M}$ acetic acid (1:50 w/v) and porcine pepsin (20 U/g residue) was added. The mixture was continuously stirred for $48 \mathrm{~h}$, followed by centrifugation, precipitation and dialysis as described above. The resulting precipitates were freeze-dried and referred to as "Pepsin-soluble collagen from paddlefish (PSC-P)" and "Pepsin-soluble collagen from globefish (PSC-G)".

\subsection{Proximate analysis}

Moisture, ash, crude protein and fat of raw materials and extracted collagens were measured according to the procedures of AOAC method No. 950.46B, 920.153, 981.10, 960.39 (a) (Association of Official Analytical Chemists, 2003).

\subsection{Yield of collagen}

The hydroxyproline content was determined according to the method of Reddy \& Enwemeka (1996). The yield was calculated as follows (Equation 1):

$$
\text { Yield }(\%)=\frac{\begin{array}{c}
\text { Hydroxyproline content in collagen }(\mathrm{mg} / \mathrm{g}) \times \\
\text { dry weight of collagen }(\mathrm{g})
\end{array}}{\begin{array}{c}
\text { Hydroxyproline content in raw material }(\mathrm{mg} / \mathrm{g}) \times \\
\text { dry weight of raw material }(\mathrm{g})
\end{array}} \times 100
$$

\subsection{Amino acid composition}

Amino acid composition was determined according to the method of Zou et al. (2015) with a slight modification. Samples were hydrolyzed under reduced pressure with $6 \mathrm{M} \mathrm{HCl}$ at $110^{\circ} \mathrm{C}$ in the absence of oxygen and then vaporized. The residue was dissolved in $25 \mathrm{~mL}$ citric acid buffer and applied to an amino acid analyzer (835-50, Hitachi Ltd., Tokyo, Japan).

\subsection{SDS-polyacrylamide gel electrophoresis (SDS-PAGE)}

Electrophoresis was performed following the procedure of Laemmli (1970). Samples were dissolved in the loading buffer (60 mM Tris- $\mathrm{HCl}, \mathrm{pH}$ 8.0, containing 25\% glycerol, 2\% SDS and $0.1 \%$ bromophenol blue) in the presence of $\beta$-mercaptoethanol, and then loaded onto a polyacrylamide-gel made of $7.0 \%$ running gel and $4.0 \%$ stacking gel. The electrophoresis was performed with an electrophoresis system (DYCZ-25D, Liuyi Ltd., Beijing, China).

\subsection{Fourier Transform Infrared (FTIR) Spectroscopy}

The spectra were recorded using an infrared spectrophotometer (200SXV, Nicolet Ltd., WI, USA) at a data acquisition rate of $2 \mathrm{~cm}^{-1}$ per point (Li et al., 2013).

\subsection{Determination of denaturation temperature}

The denaturation temperature $\left(T_{\mathrm{d}}\right)$ was obtained by measuring the viscosity using a circumvolving viscometer (MCR101, Anton Parr Ltd., Shanghai, China) (Kozlowska et al., 2015). Fractional viscosity was calculated as (Equation 2):

Fractional viscosity $=\left(\eta_{\mathrm{sp}(\text { measured })}-\eta_{\mathrm{sp}(\text { minimum })}\right) /\left(\eta_{\mathrm{sp}(\text { maximum })}-\eta_{\mathrm{sp}(\text { minimum })}\right)$

where $\eta_{\mathrm{sp}}$ is the specific viscosity. $T_{\mathrm{d}}$ was determined as the temperature at which the change in viscosity decreased $50 \%$.

\subsection{Determination of fibril-forming ability in vitro}

Fibril-forming ability was measured following method of Zhang et al. (2014b) with slight modifications. Samples were redissolved in $0.5 \mathrm{M}$ acetic acid to a concentration of $3 \mathrm{mg} / \mathrm{mL}$. The solution was mixed with two volumes of $0.1 \mathrm{M}$ phosphate buffer ( $\mathrm{pH} 7.0)$ containing $\mathrm{NaCl}$ at 0 and $150 \mathrm{mM}$, respectively. The final $\mathrm{pH}$ was adjusted to neutral $(7.0 \pm 0.2)$ and the solution was kept at $25 \pm 1{ }^{\circ} \mathrm{C}$. The turbidity change of the solution was measured at $310 \mathrm{~nm}$ using a spectrophotometer (UV-2550, Shimadzu Ltd., Kyoto, Japan). After the fibril formation experiment, the mixture was centrifuged at $5000 \times g$ for $15 \mathrm{~min}$. Fibril formation degree was calculated as the percentage of the decrease of protein concentration in the supernatant.

\subsection{Transmission electron microscopy (TEM)}

Fibril samples were loaded on 200 mesh copper grids and stained with $1 \%$ phosphotungstic acid (Li \& Douglas, 2013). TEM images were observed using a transmission electron microscopy (JSM-1200, JEOL Ltd., Tokyo, Japan).

\subsection{Scanning electron microscopy (SEM)}

Fibril samples were fixed with $2.5 \%$ glutaraldehyde for $12 \mathrm{~h}$ (Zhang et al., 2014b). After dehydration in a graded series of ethanol, fibrils were dried in a critical point dryer (HCP-2, 
Hitachi Ltd., Tokyo, Japan). The SEM images were observed using a scanning electron microscopy (JSM-840, JEOL Ltd., Tokyo, Japan).

\subsection{Statistical analysis}

An analysis of variance (ANOVA) followed by Duncan's multiple comparison test was used for comparisons by SPSS 17.0 software (SPSS Inc., Chicago, IL, USA). Mean values with standard deviations (SD) were reported. Difference was considered to be significant if $p<0.05$.

\section{Results and discussion}

\subsection{Proximate analysis}

The proximate composition of paddlefish and globefish skins were moisture $(60.13 \pm 2.13 \%$ and $69.27 \pm 1.57 \%)$, ash $(1.32 \pm 0.08 \%$ and $3.24 \pm 0.38 \%)$, protein $(32.74 \pm 1.34 \%$ and $27.53 \pm 0.63 \%)$ and fat $(5.26 \pm 0.56 \%$ and $1.47 \pm 0.21 \%)$, respectively. The protein content in paddlefish $(32.74 \%)$ and globefish $(27.53 \%)$ skins was higher than those of Spanish mackerel (17.17\%) and Nile perch (21.6\%) (Muyonga et al., 2004; Li et al., 2013). Presence of higher content of protein made the skins of paddlefish and globefish a better source for aquatic collagen extraction. The yield of different collagen samples were $53.01 \pm 3.27 \%$ (ASC-P), $65.87 \pm 6.76 \%$ (PSC-P), $62.36 \pm 5.99 \%$ (ASC-G), and 67.25 $\pm 4.68 \%$ (PSC-G), respectively. Compared with ASC-P, the yield of PSC-P was markedly increased $(p<0.05)$. Isolated collagens had high protein contents (88.42-91.13\%), low ash (1.04-1.26\%) and fat (0.12-0.22\%) contents, indicating the efficacy of removal of impurities.

\subsection{Amino acid composition}

As shown in Table 1, glycine contents of ASC-G and PSC-G (359.3-362.5 residues/1000 residues) was higher than that of ASC-P and PSC-P (342.8-349.8 residues/1000 residues), and those reported for giant grouper, unicorn leatherjacket and bester sturgeon (319-344 residues/1000 residues) (Ahmad et al., 2010; Zhang et al., 2014b; Hsieh et al., 2016). The imino acid contents of collagens derived from the skin byproducts of paddlefish and globefish were 194.1-197.9 and 186.4-189.7 residues/1000 residues, respectively, which were analogous to that of unicorn leatherjacket (187-190 residues/1000 residues) (Ahmad et al., 2010), whilst higher than those of cold water fish such as cod and deep-sea redfish (154 and 165 residues/1000 residues) (Wang et al., 2008; Zhang et al., 2009a). The less content of imino acid could lead to inferior thermal stability and lower melting point (Singh et al., 2011).

The contents of hydrophobic amino acids of collagens derived from the skin byproducts of paddlefish and globefish were calculated as 643.8-649.0 and 664.9-667.3 residues/1000 residues, respectively. Glycine was the major amino acid which may contribute to the antioxidant activity since glycine could quench unpaired electrons or radicals by supporting protons (Zhang et al., $2009 b)$. It has been reported that collagen-derived hydrolysates with hydrophobic amino acids exhibited stronger antioxidant activity (Vercruysse et al., 2009). This result indicated collagens from paddlefish and globefish skin byproducts could be utilized to produce antioxidant peptides as food additives.

\subsection{SDS-PAGE}

All extracted collagens composed at least two $\alpha$-chains (a1 and a2) as their major subunits, high molecular weight components including $\beta$ - and $\gamma$-chains were also observed (Figure 1). Subunit compositions of ASC-P, PSC-P, ASC-G and PSC-G were similar to previous reports for skin collagens from other fish species (Ahmad et al., 2010; Zhang et al., 2014b; Hsieh et al., 2016), suggesting the pattern of extracted collagens might be type I. Slight differences were also observed from the SDS-PAGE data. The molecular weight of protein bands of ASC-G and PSC-G was slightly higher than those of ASC-P and PSC-P. In addition, constituents with approximate molecular weight in the range of $130-200 \mathrm{kDa}$ were observed between $\beta$ - and $\alpha$-chains for ASC-P and PSC-P. Moreover, ASC-P and PSC-P contained two $\gamma$-chains, whilst only one major $\gamma$-chain was found in ASC-G and PSC-G. This result indicated that the intra- and/or inter-molecular crosslinks were richer in paddlefish skin collagens.

\subsection{FTIR}

The FTIR spectra are shown in Figure 2. Amide A is related to $\mathrm{N}-\mathrm{H}$ stretching, the wavenumber occurs in the range of $3400-3440 \mathrm{~cm}^{-1}$ and moves to lower frequency when N-H groups

Table 1. Amino acid compositions of collagens from the skin byproducts of paddlefish (ASC-P and PSC-P) and globefish (ASC-G and PSC-G) (residues/1000 residues).

\begin{tabular}{|c|c|c|c|c|}
\hline Amino acids & ASC-P & PSC-P & ASC-G & PSC-G \\
\hline Aspartic acid (Asp) & 41.9 & 43.5 & 44.9 & 43.5 \\
\hline Threonine (Thr) & 25.0 & 22.5 & 17.6 & 19 \\
\hline Serine (Ser) & 44.8 & 47.0 & 36.4 & 34.9 \\
\hline Glutamine acid (Glu) & 67.6 & 60.5 & 69.2 & 67.2 \\
\hline Glycine (Gly) & 349.8 & 342.8 & 362.5 & 359.3 \\
\hline Alanine (Ala) & 109.8 & 115.3 & 123.9 & 120.4 \\
\hline Cysteine (Cys) & 3.1 & 2.0 & 0.7 & 1.5 \\
\hline Valine (Val) & 20.8 & 22.9 & 22.3 & 23.7 \\
\hline Methionine (Met) & 12.2 & 13.9 & 12.5 & 13.1 \\
\hline Isoleucine (Ile) & 11.2 & 10.1 & 8.1 & 9.7 \\
\hline Leucine (Leu) & 17.2 & 16.1 & 16.7 & 17.5 \\
\hline Tyrosine (Tyr) & 8.4 & 9.6 & 2.1 & 4.5 \\
\hline Phenylalanine (Phe) & 14.0 & 15.5 & 12.1 & 13.6 \\
\hline Hydroxylysine (Hyl) & 7.6 & 8.2 & 6.1 & 6.7 \\
\hline Histidine (His) & 4.2 & 5.0 & 6.8 & 7.4 \\
\hline Lysine (Lys) & 24.2 & 24.9 & 24.5 & 23.6 \\
\hline Arginine (Arg) & 44.1 & 42.3 & 47.2 & 44.7 \\
\hline Proline (Pro) & 108.8 & 112.4 & 109.2 & 107.6 \\
\hline Hydroxyproline (Hyp) & 85.3 & 85.5 & 77.2 & 82.1 \\
\hline Total & 1000.0 & 1000.0 & 1000.0 & 1000.0 \\
\hline Imino acid & 194.1 & 197.9 & 186.4 & 189.7 \\
\hline THAA & 643.8 & 649.0 & 667.3 & 664.9 \\
\hline
\end{tabular}

Imino acid: Proline + Hydroxyproline, THAA (Total hydrophobic amino acids): $\Sigma$ Proline + Alanine + Valine + Methionine + Glycine + Isoleucine + Leucine + Phenylalanine 
involved in formation of hydrogen bonds (Doyle et al., 1975). The Amide A bands of ASC-P, PSC-P, ASC-G and PSC-G were found at 3322.4, 3325.3, 3324.5 and $3326.8 \mathrm{~cm}^{-1}$ respectively, indicating more hydrogen bonds in PSC-P and PSC-G were degraded by pepsin treatment during extraction process. The Amide B bands of ASC-P, PSC-P, ASC-G and PSC-G were found at 2926.4, 2927.1, 2928.5 and $2929.3 \mathrm{~cm}^{-1}$, respectively. The Amide B band intensity of ASC-P and PSC-P were relatively stronger than those of ASC-G and PSC-G, suggesting the more $\mathrm{CH}_{2}$ asymmetrical stretches in paddlefish skin collagens.

The wavenumbers of Amide I, II and III bands were related to the collagen configurations. Amide I band is originated from $\mathrm{C}=\mathrm{O}$ stretching vibrations or hydrogen bonds coupled with $\mathrm{COO}^{-}$, and was the sensitive marker of protein secondary structure (Payne \& Veis, 1988). Amide II band is associated with the $\mathrm{N}-\mathrm{H}$ bending coupled with C-N stretching. Amide III band represented the $\mathrm{C}-\mathrm{N}$ stretching and $\mathrm{N}-\mathrm{H}$ deformation from amide linkages as well as the absorption caused by the wagging vibration of $\mathrm{CH}_{2}$

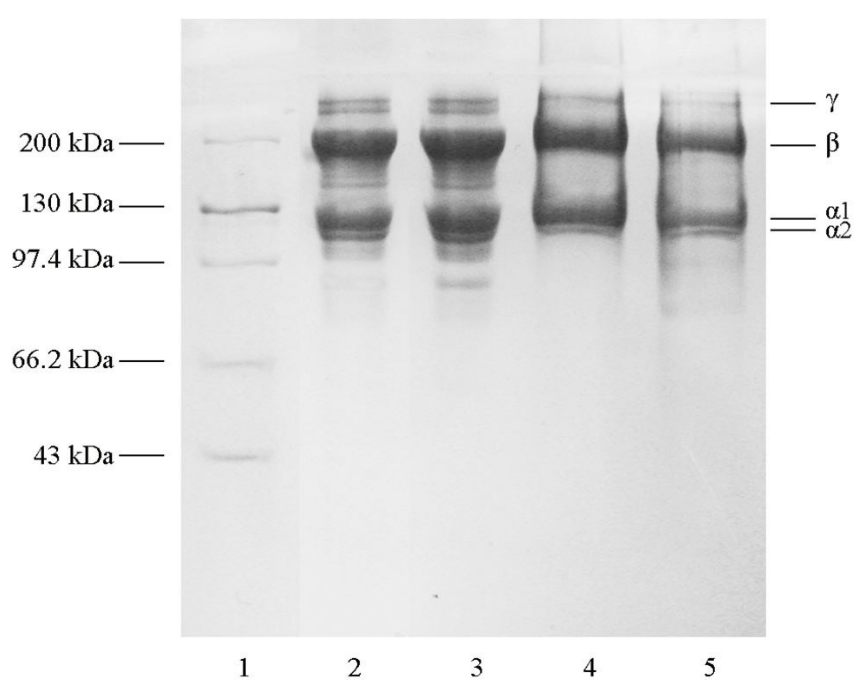

Figure 1. SDS-PAGE patterns of collagens from the skin byproducts of paddlefish (ASC-P and PSC-P) and globefish (ASC-G and PSC-G). Lane 1: protein marker; lane 2: ASC-P; lane 3: PSC-P; lane 4: ASC-G; lane 5: PSC-G.

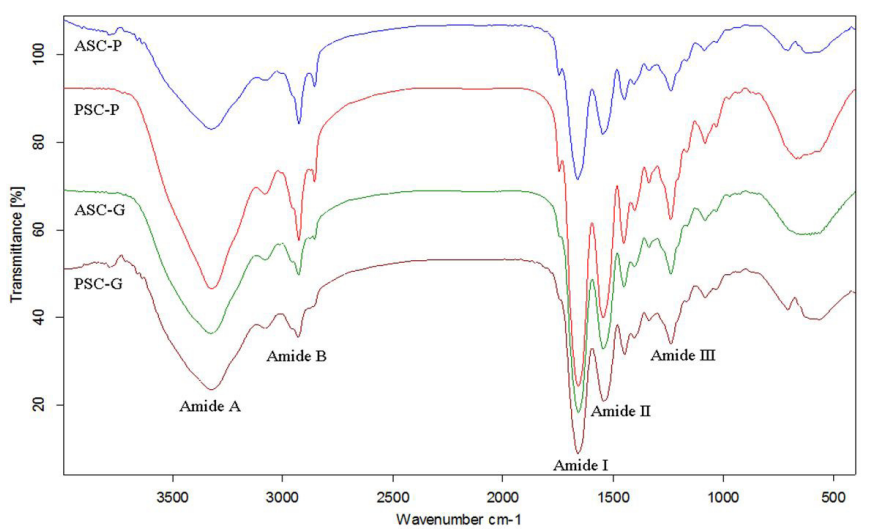

Figure 2. FTIR spectra of collagens from the skin byproducts of paddlefish (ASC-P and PSC-P) and globefish (ASC-G and PSC-G). groups of the glycine backbone and the proline side-chains (Cozza et al., 2016). No differences in Amide I $\left(1658.7-1661.1 \mathrm{~cm}^{-1}\right)$, II (1545.2-1548.3 $\left.\mathrm{cm}^{-1}\right)$ and III bands (1237.4-1238.4 $\left.\mathrm{cm}^{-1}\right)$ were observed among ASC-P, PSC-P, ASC-G and PSC-G, indicating the similarity in intramolecular assignments of four extracted collagens. Additionally, absorption bands around $1450 \mathrm{~cm}^{-1}$ were also observed in ASC-P $\left(1449.3 \mathrm{~cm}^{-1}\right)$, PSC-P $\left(1452.9 \mathrm{~cm}^{-1}\right)$, ASC-G $\left(1448.8 \mathrm{~cm}^{-1}\right)$ and PSC-G $\left(1451.4 \mathrm{~cm}^{-1}\right)$, which intensively corresponded to the pyrrolidine ring vibration of proline and hydroxyproline (Pal et al., 2015).

\subsection{Determination of denaturation temperature}

$T_{\mathrm{d}}$ values of ASC-P, PSC-P, ASC-G and PSC-G were 29.6, 28.2, 27.4 and $26.9^{\circ} \mathrm{C}$, respectively (Figure 3 ), which were higher than those of deep-sea redfish $\left(16.1^{\circ} \mathrm{C}\right)$ and Spanish mackerel (14.7-15.1 ${ }^{\circ} \mathrm{C}$ ) (Wang et al., 2008; Li et al., 2013). The results were in agreement with previous reports that $T_{\mathrm{d}}$ was correlated with the imino acid content which contributed to the structural integrity of collagen (Singh et al., 2011). $T_{d}$ of ASCs was higher than their corresponding PSCs, which might be caused by the molecular weight reduction in telopeptide regions due to the pepsin hydrolysis. Additionally, $T_{\mathrm{d}}$ of ASC-P, PSC-P, ASC-G and PSC-G were higher than those of several invertebrates, including Cyanea nozakii jellyfish $\left(23.8^{\circ} \mathrm{C}\right)$ and Loligo vulgaris squid $\left(21-22^{\circ} \mathrm{C}\right)$ (Cozza et al., 2016; Zhang et al., 2014a). Therefore ASCs and PSCs from the skin byproducts of paddlefish and globefish might be used as a better source for collagen-based materials.

\subsection{Fibril-forming ability in vitro}

As shown in Figure 4a, irrespective of fish species, the time-turbidity curves of extracted samples with lag, growth and plateau phases were observed. The first step is a lag phase without detectable change in turbidity, representing the aggregation of collagen molecules to form dimers and trimers. The second step is a growth phase during which turbidity changes rapidly, it corresponds to the growing cores of fibrils. The third step is a plateau phase where turbidity stops

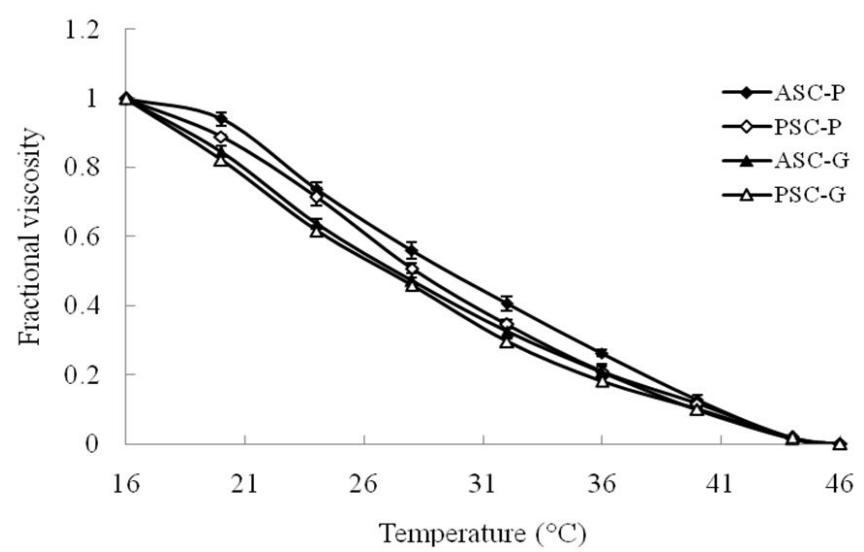

Figure 3. Thermal denaturation temperatures of collagens from the skin byproducts of paddlefish (ASC-P and PSC-P) and globefish (ASC-G and PSC-G), as shown by changes in fractional viscosity. 


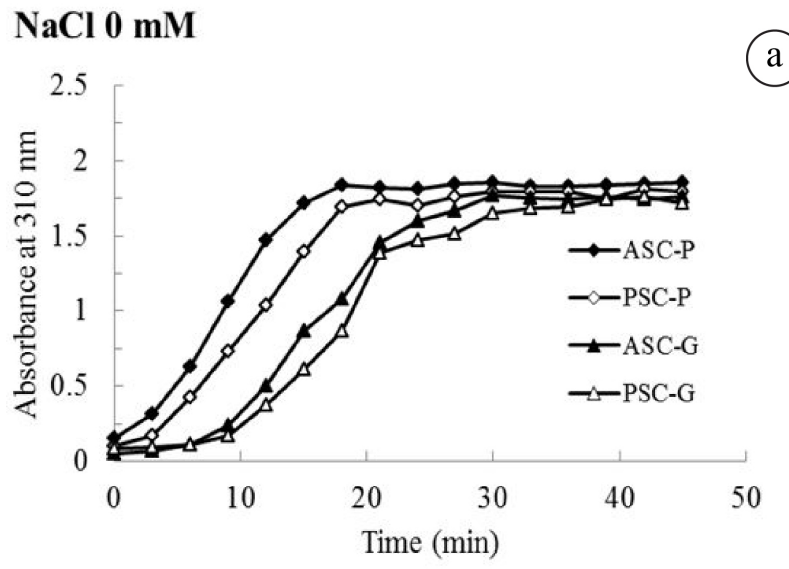

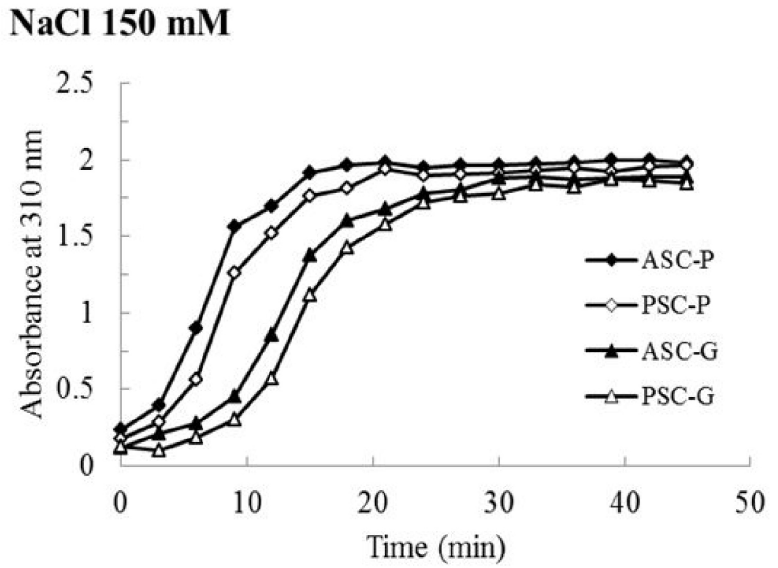

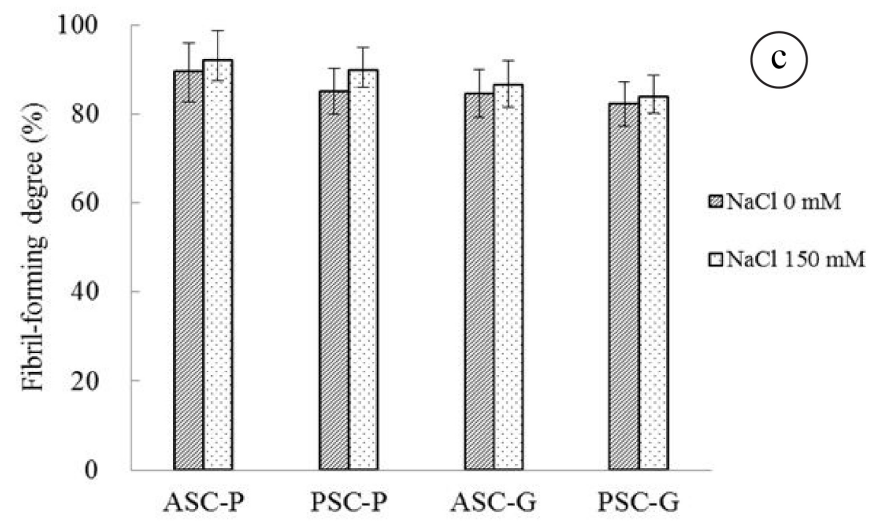

Figure 4. Effect of $\mathrm{NaCl}$ concentration on turbidity changes ( $\mathrm{a}, \mathrm{b})$ and fibril-forming degree (c) of collagens from the skin byproducts of paddlefish (ASC-P and PSC-P) and globefish (ASC-G and PSC-G).

increasing, suggesting the formation of the three-dimensional networks of fibrils (Sai \& Babu, 2001; Zhang et al., 2014b). The fibril-forming rate of ASC-P and PSC-P was more rapid than that of ASC-G and PSC-G. Additionally, ASCs exhibited a slightly rapid rise in turbidity than their corresponding PSCs, since the telopeptide regions at the $\mathrm{N}$ - and C-termini are important in stabilizing initial aggregates, enzymatic digestion of the telopeptide regions might inhibit the fibril formation process (Li \& Douglas, 2013).

An apparent acceleration in lag and growth phases was observed by the addition of $\mathrm{NaCl}$ (Figure $4 \mathrm{~b}$ ). The fibril-forming degree of four samples ranged from $82.26 \%$ to $89.40 \%$, which were slightly up-regulated in the presence of $\mathrm{NaCl}(p>0.05)$ (Figure 4c). This result was in accordance with previous reports for collagen from bester sturgeon skin (Zhang et al., 2014b), suggesting that ions might bind to the regions with excess charge density and accelerate protein monomers register longitudinally to form fibrils. However, the fibril-forming rate and degree of collagen from salmon skin and jellyfish were suppressed by the addition of $\mathrm{NaCl}$ (Yunoki et al., 2004; Hoyer et al., 2014), indicating fibrillogenesis is highly sensitive to collagen sources, the experimental conditions and the disparity in structural information which encoded in primary sequences (Tang et al., 2015).

\subsection{TEM observation of fibrils}

During the fibril-forming process, the side-to-side aggregation of collagen molecules produces alternating regions of protein density in the fibril, gap and overlap zones exist within the fibril and produce an oscillating surface topography with a characteristic axial repeat pattern which is referred to as the D-periodicity (Kadler et al., 1996). All four samples could assemble into uniform parallel-sided fibrils with characteristic D-periodicity (Figure 5). The average D-periodicity of ASC-G $(66.90 \pm 2.35 \mathrm{~nm})$ and PSC-G $(66.88 \pm 2.17 \mathrm{~nm})$ was slightly smaller than that of ASC-P $(67.95 \pm 2.07 \mathrm{~nm})$ and PSC-P $(67.58 \pm 1.89 \mathrm{~nm})(p>0.05)$. Studies have shown that D-periodicity served as an indication for the reconstruction of native-like fibrils which are important in maintaining mechanical stability and biological functions of load-bearing materials (Li \& Douglas, 2013). Fibrils with native D-periodicity also play an important role in mineralization by providing structure templates where minerals are deposited in the gap zones of fibrils (Nudelman et al., 2010). Thus, collagens extracted from paddlefish and globefish skin byproducts could 


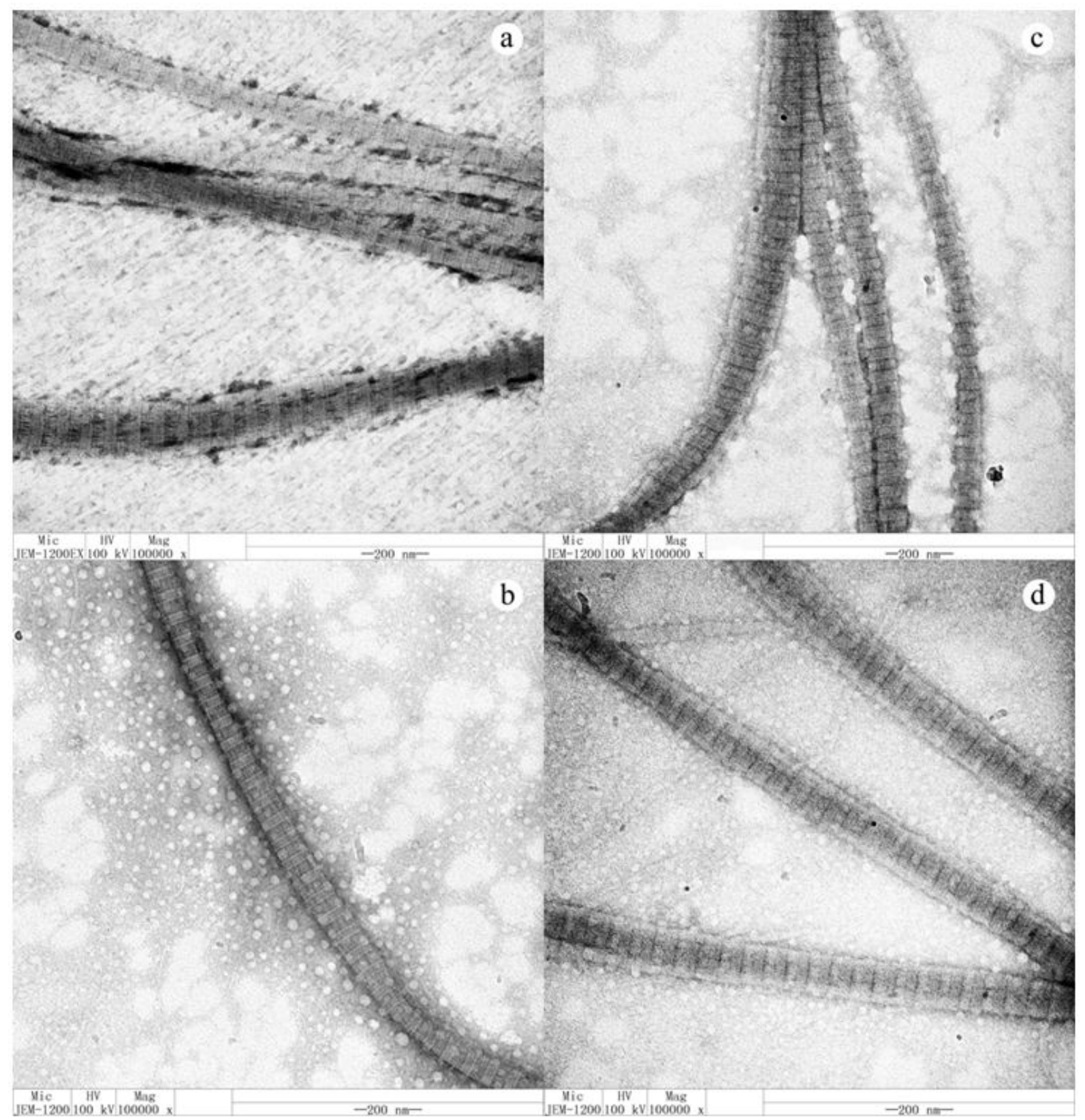

Figure 5. TEM observations of fibrils formed by collagens from the skin byproducts of paddlefish (ASC-P and PSC-P) (a, b) and globefish (ASC-G and PSC-G) (c, d).

be utilized as a novel source of biomaterials and food-packaging films.

\subsection{SEM observation of fibrils}

The morphologies of four fibrils after $1 \mathrm{~h}$ incubation are shown in Figure 6a-d. Fibrils derived from paddlefish and globefish skin byproducts exhibited a branched and interlaced microstructure. The diameter of the four samples was at around 70-120 nm, which was similar to the native fibrils formed in vivo (De Wild et al., 2013).

SEM images of collagen fibrils after $24 \mathrm{~h}$ incubation are shown in Figure 6e-h. A longer incubation time lead to an increase in fibril diameter, slender fibrils laterally aggregated into bundles and fused into one large compactly interwoven structure. The thickness distribution of fibril bundles after $24 \mathrm{~h}$ incubation was more inhomogeneous than that after $1 \mathrm{~h}$ incubation. In addition, the width of fibril bundles of ASC-P and PSC-P (Figure 6e-f) was thicker than those of ASC-G and PSC-G (Figure 6g-h), indicating collagen derived from paddlefish skin byproducts may have a better fibril-forming ability. Moreover, the fibril morphologies of extracted collagens were different with that of collagens from catla skin, which had nodular-like structures (Pal et al., 2015). The differences in morphological characteristics might be illustrated by the differences in the species and conformations of collagens. In view of the increasing 


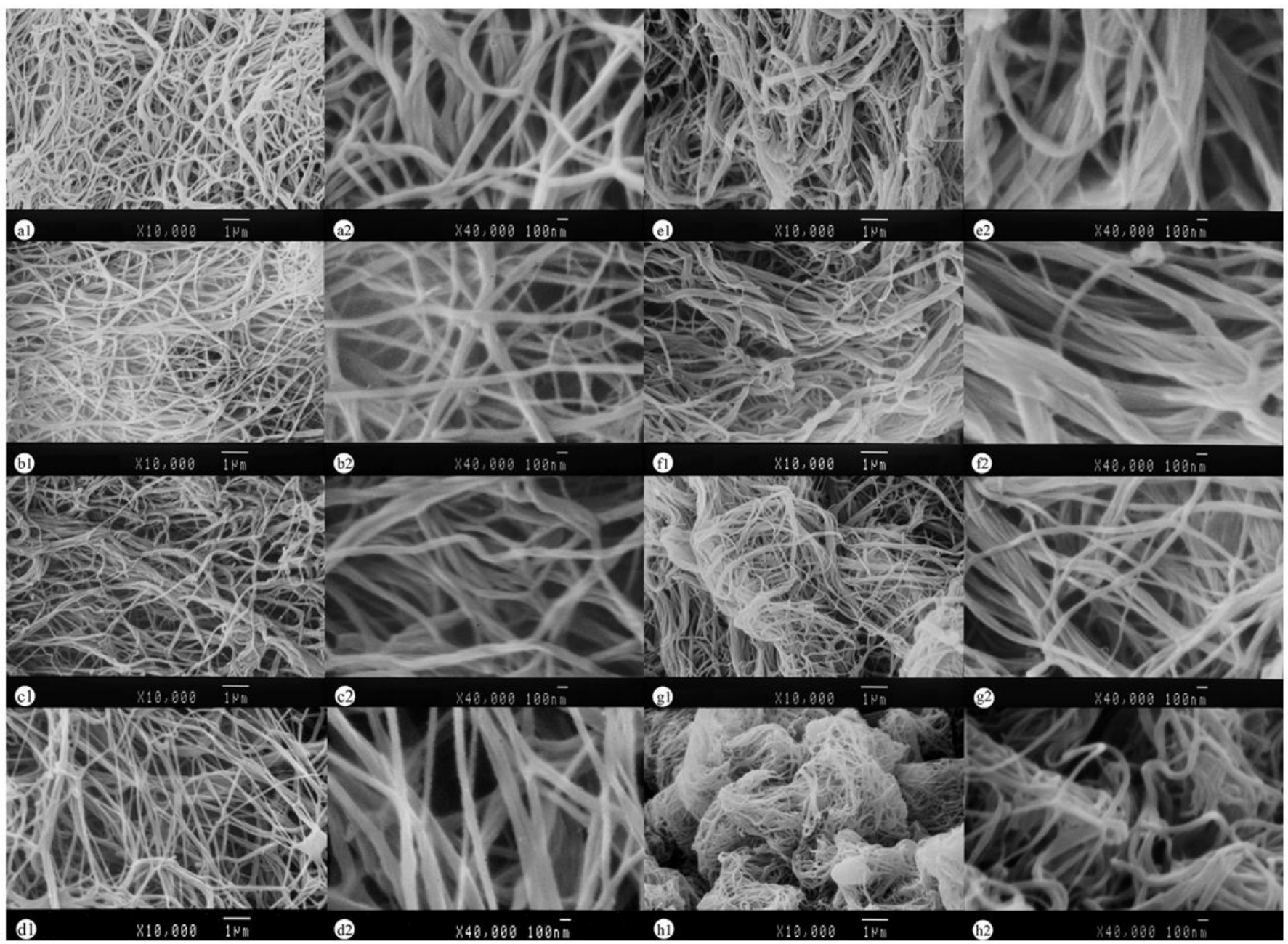

Figure 6. SEM observations of fibrils formed by collagens from the skin byproducts of paddlefish (ASC-P and PSC-P) and globefish (ASC-G and PSC-G). (a-d): ASC-P, PSC-P, ASC-G and PSC-G incubated for $1 \mathrm{~h}$; (e-h): ASC-P, PSC-P, ASC-G and PSC-G incubated for 24 h.

applications of collagen-based materials, ASCs and PSCs from paddlefish and globefish have the potential to serve as tissue engineering scaffolds, 3D cell culture systems and food-packaging films. Therefore it is necessary to get their fundamental information of molecular basis and in vitro fibril-forming abilities in order to control the formation of target materials.

\section{Conclusions}

This study investigated the physicochemical and fibril-forming properties of collagens purified from the skin byproducts of paddlefish (ASC-P and PSC-P) and globefish (ASC-G and PSC-G). All four samples were characterized as type I collagen with slight molecular structure differences. TEM and SEM observations confirmed the well-defined fibril morphologies. ASC-P and PSC-P exhibited relatively higher thermal stabilities and better fibril-forming abilities compared with ASC-G and PSC-G. These results suggested that collagens derived from the paddlefish and globefish skin byproducts could serve as an alternative source to mammalian counterpart for further industrial purposes.

\section{Acknowledgements}

The study was supported by the National Science Technology Support Plan Projects (2015BAD17B01) and Qingdao Postdoctoral Application Research Project.

\section{References}

Ahmad, M., Benjakul, S., \& Nalinanon, S. (2010). Compositional and physicochemical characteristics of acid solubilized collagen extracted from the skin of unicorn leatherjacket (Aluterus monoceros). Food Hydrocolloids, 24(6), 588-594. http://dx.doi.org/10.1016/j. foodhyd.2010.03.001.

Association of Official Analytical Chemists - AOAC. (2003). Official methods of analysis of the Association of Official Analytical Chemists (17th ed.). Gaithersburg: AOAC.

Cozza, N., Bonani, W., Motta, A., \& Migliaresi, C. (2016). Evaluation of alternative sources of collagen fractions from Loligo vulgaris squid mantle. International Journal of Biological Macromolecules, 87, 504-513. PMid:26972602. http://dx.doi.org/10.1016/j.ijbiomac.2016.03.013.

De Wild, M., Pomp, W., \& Koenderink, G. H. (2013). Thermal memory in self-assembled collagen fibril networks. Biophysical Journal, 105(1), 200-210. PMid:23823240. http://dx.doi.org/10.1016/j.bpj.2013.05.035. 
Doyle, B. B., Bendit, E. G., \& Blout, E. R. (1975). Infrared spectroscopy of collagen and collagen-like polypeptides. Biopolymers, 14(5), 937957. PMid:1156652. http://dx.doi.org/10.1002/bip.1975.360140505.

Exposito, J., Valcourt, U., Cluzel, C., \& Lethias, C. (2010). The fibrillar collagen Family. International Journal of Molecular Sciences, 11(2), 407-426. PMid:20386646. http://dx.doi.org/10.3390/ijms11020407.

Hoyer, B., Bernhardt, A., Lode, A., Heinemann, S., Sewing, J., Klinger, M., Notbohm, H., \& Gelinsky, M. (2014). Jellyfish collagen scaffolds for cartilage tissue engineering. Acta Biomaterialia, 10(2), 883-892. PMid:24184178. http://dx.doi.org/10.1016/j.actbio.2013.10.022.

Hsieh, C. H., Shiau, C. Y., Su, Y. C., Liu, Y. H., \& Huang, Y. R. (2016). Isolation and characterization of collagens from the skin of giant grouper (Epinephelus lanceolatus). Journal of Aquatic Food Product Technology, 25(1), 93-104. http://dx.doi.org/10.1080/10498850.20 13.828145 .

Kadler, K. E., Holmes, D. F., Trotter, J. A., \& Chapman, J. A. (1996). Collagen fibril formation. The Biochemical Journal, 316(1), 1-11. PMid:8645190. http://dx.doi.org/10.1042/bj3160001.

Kozlowska, J., Sionkowska, A., Skopinska-Wisniewska, J., \& Piechowicz, K. (2015). Northern pike (Esox lucius) collagen: Extraction, characterization and potential application. International Journal of Biological Macromolecules, 81, 220-227. PMid:26254247. http:// dx.doi.org/10.1016/j.ijbiomac.2015.08.002.

Laemmli, U. K. (1970). Cleavage of structural proteins during the assembly of the head of bacteriophage T4. Nature, 227(5259), 680685. PMid:5432063. http://dx.doi.org/10.1038/227680a0.

Li, Y., \& Douglas, E. P. (2013). Effects of various salts on structural polymorphism of reconstituted type I collagen fibrils. Colloids and Surfaces. B, Biointerfaces, 112, 42-50. PMid:23948153. http://dx.doi. org/10.1016/j.colsurfb.2013.07.037.

Li, Z. R., Wang, B., Chi, C. F., Zhang, Q. H., Gong, Y. D., Tang, J. J., Luo, H. Y., \& Ding, G. F. (2013). Isolation and characterization of acid soluble collagens and pepsin soluble collagens from the skin and bone of Spanish mackerel (Scomberomorous niphonius). Food Hydrocolloids, 31(1), 103-113. http://dx.doi.org/10.1016/j. foodhyd.2012.10.001.

Muyonga, J. H., Cole, C. G., \& Duodu, K. G. (2004). Characterisation of acid soluble collagen from skins of young and adult Nile perch (Lates niloticus). Food Chemistry, 85(1), 81-89. http://dx.doi.org/10.1016/j. foodchem.2003.06.006.

Nudelman, F., Pieterse, K., George, A., Bomans, P. H., Friedrich, H., Brylka, L. J., Hilbers, P. A. J., With, G. D., \& Sommerdijk, N. A. J. M. (2010). The role of collagen in bone apatite formation in the presence of hydroxyapatite nucleation inhibitors. Nature Materials, 9(12), 1004-1009. PMid:20972429. http://dx.doi.org/10.1038/nmat2875.

Pal, G. K., Nidheesh, T., \& Suresh, P. V. (2015). Comparative study on characteristics and in vitro fibril formation ability of acid and pepsin soluble collagen from the skin of catla (Catla catla) and rohu (Labeo rohita). Food Research International, 76(3), 804-812. http://dx.doi. org/10.1016/j.foodres.2015.07.018.

Payne, K. J., \& Veis, A. (1988). Fourier transform IR spectroscopy of collagen and gelatin solutions: deconvolution of the amide I band for conformational studies. Biopolymers, 27(11), 1749-1760. PMid:3233328. http://dx.doi.org/10.1002/bip.360271105.

Reddy, G. K., \& Enwemeka, C. S. (1996). A simplified method for the analysis of hydroxyproline in biological tissues. Clinical Biochemistry, 29(3), 225-229. PMid:8740508. http://dx.doi.org/10.1016/00099120(96)00003-6.

Sai, K. P., \& Babu, M. (2001). Studies on rana tigerina, skin collagen. Comparative Biochemistry and Physiology. Part B, Biochemistry \&
Molecular Biology, 128(1), 81-90. PMid:11163307. http://dx.doi. org/10.1016/S1096-4959(00)00301-8.

Shi, P. S., Wang, Q., Zhu, Y. T., Gu, Q. H., \& Xiong, B. X. (2013). Comparative study on muscle nutritional composition of juvenile bighead carp (Aristichthys nobilis) and paddlefish (Polyodon spathula) fed live feed. Turkish Journal of Zoology, 37(3), 321-328. http://dx.doi. org/10.3906/zoo-1206-24.

Singh, P., Benjakul, S., Maqsood, S., \& Kishimura, H. (2011). Isolation and characterisation of collagen extracted from the skin of striped catfish (Pangasianodon hypophthalmus). Food Chemistry, 124(1), 97-105. http://dx.doi.org/10.1016/j.foodchem.2010.05.111.

Suárez-Jiménez, G. M., Robles-Sánches, R. M., Yépiz-Plascencia, G., Burgos-Hernández, A., \& Ezquerra-Brauer, J. M. (2015). In vitro antioxidant, antimutagenic and antiproliferative activities of collagen hydrolysates of jumbo squid (Dosidicus gigas) byproducts. Food Science and Technology, 35(3), 421-427. http://dx.doi.org/10.1590/1678457X.6658.

Tang, L., Chen, S., Su, W., Weng, W., Osako, K., \& Tanaka, M. (2015). Physicochemical properties and film-forming ability of fish skin collagen extracted from different freshwater species. Process Biochemistry, 50(1), 148-155. http://dx.doi.org/10.1016/j.procbio.2014.10.015.

Tao, N., Wang, L., Gong, X., \& Liu, Y. (2012). Comparison of nutritional composition of farmed pufferfish muscles among Fugu obscurus, Fugu flavidus and Fugu rubripes. Journal of Food Composition and Analysis, 28(1), 40-45. http://dx.doi.org/10.1016/j.jfca.2012.06.004.

Vercruysse, L., Smagghe, G., Beckers, T., \& Camp, J. V. (2009). Antioxidative and ACE inhibitory activities in enzymatic hydrolysates of the cotton leafworm, Spodoptera littoralis. Food Chemistry, 114(1), 38-43. http:// dx.doi.org/10.1016/j.foodchem.2008.09.011.

Wang, L., An, X., Yang, F., Xin, Z., Zhao, L., \& Hu, Q. (2008). Isolation and characterisation of collagens from the skin, scale and bone of deep-sea redfish (Sebastes mentella). Food Chemistry, 108(2), 616-623. PMid:26059140. http://dx.doi.org/10.1016/j.foodchem.2007.11.017.

Yunoki, S., Nagai, N., Suzuki, T., \& Munekata, M. (2004). Novel biomaterial from reinforced salmon collagen gel prepared by fibril formation and cross-linking. Journal of Bioscience and Bioengineering, 98(1), 40-47. PMid:16233664. http://dx.doi.org/10.1016/S1389-1723(04)70240-6.

Zhang, J., Duan, R., Tian, Y., \& Konno, K. (2009a). Characterisation of acid-soluble collagen from skin of silver carp (Hypophthalmichthys molitrix). Food Chemistry, 116(1), 318-322. http://dx.doi.org/10.1016/j. foodchem.2009.02.053.

Zhang, J., Zhang, H., Wang, L., Guo, X., Wang, X., \& Yao, H. (2009b). Antioxidant activities of the rice endosperm protein hydrolysate: identification of the active peptide. European Food Research and Technology, 229(4), 709-719. http://dx.doi.org/10.1007/s00217009-1103-3.

Zhang, J., Duan, R., Huang, L., Song, Y., \& Regenstein, J. M. (2014a). Characterisation of acid-soluble and pepsin-solubilised collagen from jellyfish (Cyanea nozakii Kishinouye). Food Chemistry, 150, 22-26. PMid:24360414. http://dx.doi.org/10.1016/j.foodchem.2013.10.116.

Zhang, X., Ookawa, M., Tan, Y., Ura, K., Adachi, S., \& Takagi, Y. (2014b). Biochemical characterisation and assessment of fibril-forming ability of collagens extracted from Bester sturgeon Huso huso $\times$ Acipenser ruthenus. Food Chemistry, 160, 305-312. PMid:24799243. http:// dx.doi.org/10.1016/j.foodchem.2014.03.075.

Zou, Y., Ma, K., \& Tian, M. (2015). Chemical composition and nutritive value of hot pepper seed (Capsicum annuum) grown in Northeast Region of China. Food Science and Technology, 35(4), 659-663. http://dx.doi.org/10.1590/1678-457X.6803. 